\title{
Effect of Early Nursing Intervention on Hemodynamics After Emergency PCI in Patients with AMI and Its Clinical Significance
}

\author{
Nana Liu ${ }^{1, ~ *, ~ D o n g m e i ~ Z h a o ~}{ }^{2}$, Rongjun Jiang ${ }^{1}$ \\ ${ }^{1}$ Department of Respiratory, Binzhou People's Hospital, Binzhou City, China \\ ${ }^{2}$ Department of Cardiovascular Ultrasound, Binzhou People's Hospital, Binzhou City, China
}

Email address:

liunana2019@163.com (Nana Liu)

${ }^{*}$ Corresponding author

To cite this article:

Nana Liu, Dongmei Zhao, Rongjun Jiang. Effect of Early Nursing Intervention on Hemodynamics After Emergency PCI in Patients with AMI and Its Clinical Significance. Science Journal of Public Health. Vol. 7, No. 6, 2019, pp. 193-199. doi: 10.11648/j.sjph.20190706.13

Received: September 7, 2019; Accepted: October 26, 2019; Published: November 8, 2019

\begin{abstract}
OBJECTIVE: To investigate the effect of early rehabilitation nursing procedures on hemodynamics after percutaneous coronary intervention (PCI) in patients with acute myocardial infarction. METHODS: One hundred patients with acute myocardial infarction who were admitted to our hospital from June 2018 to June 2019 were randomly divided into rehabilitation group and control group, with 50 cases in each group. The control group received routine nursing and guidance on the basis of conventional drug therapy after PCI. The rehabilitation group performed rehabilitation nursing on the basis of conventional drug therapy after PCI, including rehabilitation exercise and health education. The routine parameters of non-invasive hemodynamics were monitored and the incidence of oozing and hematoma at the puncture site and the degree of comfort change of the patients were observed. RESULTS: The preoperative hemodynamic parameters of the two groups were compared. There was no significant difference between the rehabilitation group and the control group before PCI (P>0.05). On the third day after operation, the cardiac output of $\mathrm{CO}$ after rehabilitation was significantly increased compared with that before surgery, and the difference between the two groups was statistically significant $(\mathrm{P}<0.05)$. The mean arterial pressure MAP was significantly lower than that before surgery. The difference was statistically significant $(\mathrm{P}<0.05)$. In the rehabilitation group, the bed rest and urination were significantly better than the control group $(\mathrm{P}<0.05)$. The degree of bloating discomfort was significantly lower than that of the control group $(\mathrm{P}<0.05)$, and the reduction of back pain was more significant than the control group. $\mathrm{P}<0.05)$ ). Conclusion: In patients with acute myocardial infarction (without severe comorbidities), under the strict monitoring of non-invasive hemodynamics, early rehabilitation care does not affect the patient's cardiac function and is a safe nursing measure.
\end{abstract}

Keywords: AMI Patients, PCI, Hemodynamics, Nursing Intervention

\section{Background}

Early, long-lasting, and fully open AMI-related blood vessels can save more viable myocardium, minimize infarct size, improve heart function, improve patients' quality of life, and provide protection for early rehabilitation of AMI patients after emergency PCI. Percutaneous coronary intervention (PCI) is the preferred method for acute myocardial infarction (AMI)-related arterial revascularization. The goal is to fully open the infarct-related coronary artery in the shortest possible time to achieve blood flow in the infarcted myocardial tissue. Perfusion, saving sudden cardiac muscle and maintaining left ventricular function, reducing infarct size, reducing the occurrence of coronary heart disease events, and improving clinical prognosis [1]. This technology has been recognized as one of the main methods of treatment because of its advantages of small trauma, safety, high success rate, rapid recovery, and short hospital stay [2]. The traditional path of emergency PCI is femoral artery. Because of the percutaneous femoral artery puncture, it is easy to cause hemorrhage at the puncture site to form subcutaneous 
hematoma, local pain, infection and other complications. It is necessary to brake the limb for 12 hours and routinely lying for 24 hours, which may lead to different patients. Uncomfortable degree, such as: back pain, irritability, difficulty urinating, poor sleep, no appetite, etc. [3]. Moreover, because the patient stays in bed for a long time, the rehabilitation time is prolonged, and the hospitalization cost and the nursing workload are increased. Evidence-based studies have shown that early appropriate activities in the absence of bleeding at the puncture site can improve coronary circulation and reduce postoperative discomfort and psychological stress [4]. At present, routine nursing care for PCI after surgery in China is limited to ECG monitoring for 24 hours. Observe the complications such as arrhythmia, myocardial ischemia and myocardial infarction, monitor blood pressure, prevent postoperative complications, hypotension and observe local perforation. The blood condition and the presence or absence of hematoma and the pulsation of the dorsal artery of the foot have not paid attention to the related nursing of cardiac function changes after PCI and the safety of early postoperative rehabilitation nursing [5]. There are still many concerns about the various early rehabilitation programs in practice. One of the important reasons is that most patients lack sufficient confidence in the safety of early activities due to lack of understanding of this technology.

\section{Materials and Methods}

\subsection{Research Object}

A total of 100 patients with acute myocardial infarction admitted to our hospital from June 2018 to June 2019 were enrolled. The patients were randomly divided into rehabilitation group and control group, with 50 cases in each group.

Inclusion criteria: 1 age 40 to 75 years; 2 acute myocardial infarction; 3 all patients with successful invasive percutaneous coronary intervention (PCI) for infarct-related vessels, other major coronary angiography results narrow $<60 \%$; 4 cardiac function killipI $\sim$ II; 5 agreed to exercise cardiopulmonary function determination; 6 can be followed up after discharge.

Exclusion criteria: 1 history of myocardial infarction; 2 AMI with acute pulmonary edema, severe arrhythmia and cardiogenic shock and other serious complications; 3 with left main disease; 4 with other serious diseases of the system HIV infection, malignant tumor, severe liver Primary renal disease and chronic lung disease; 5 can not exercise and cooperate [6].

\subsection{Rehabilitation Care}

The control group received routine nursing and guidance on the basis of conventional drug therapy after PCI. The rehabilitation group performed rehabilitation nursing on the basis of conventional drug therapy after PCI, including rehabilitation exercise and health education. The rehabilitation program is based on age, cardiopulmonary function, coronary artery characteristics developed by the American College of Cardiology, and the first phase (CCU period) of the three-stage rehabilitation program recommended by the American Heart Association AHA and the emergency PCI rehabilitation program developed in China. Our hospital's practical experience for rehabilitation guidance [7].

\subsection{Monitoring Indicators}

Non-invasive hemodynamic monitoring routine parameters: heart rate (HR): blood pressure: systolic blood pressure (SBP), diastolic blood pressure (DBP), mean arterial pressure (MAP). Before and after load indicators: body vascular resistance / resistance index (SVR / SVRI). Left ventricular pumping blood function indicators: cardiac output / cardiac index $(\mathrm{CO} /$ $\mathrm{CI}$ ); stroke volume / stroke index (SV / SI). Left ventricular systolic function index: left ventricular ejection time (LVET); left ventricular work/work index (LCW/LCWI), contraction time ratio (STR).

\subsection{Observation Indicators}

The incidence of oozing and hematoma at the puncture site and the degree of comfort change of the patients in the rehabilitation group and the control group were observed, including the differences in back pain, irritability, insomnia, and dysuria. 1 Puncture site damage, such as blood permeation gauze for local bleeding, local appearance of lumps and skin color changes at the puncture site, diameter greater than $4 \mathrm{~cm}$ for local hematoma. 2 dysuria: refers to the patient complained of urine and can not discharge, abdominal examination to see the upper edge of the pubic symphysis, abdominal augmentation, percussion was voiced, need catheterization to urinate. 3 insomnia: can not sleep, wake up, sleep less than $6 \mathrm{~h}$ at night. 4 poor comfort: $2 \mathrm{~h}$ after surgery, limb numbness, back pain, abdominal distension and other discomfort, can not be relieved in time after the event.

\subsection{Monitoring Methods}

1 Fix the main unit, turn on the power, turn on the main machine, wipe the skin of the electrode part with $75 \%$ ethanol gauze, and ensure that it is dry; stick the electrode patch, connect the wire, and place the white electrode on the neck of both sides. Black is placed slightly above white, red is placed on both sides of the midline scabbard level, and green is slightly below red. Pay attention to the observation and replace it when it is detached, so as not to affect the monitoring results, especially when the sweat is more. 2 Enter the correct gender, height, weight, etc., including its unit. If CVP or PAWP can be measured, enter the measured value. If not, combine with clinical analysis. 3 Pay attention to the use of special blood pressure cuff, ensure that the cuff tube is not squeezed during the measurement. During the process of filling and deflation, the patient's arm should be kept at rest and relaxed; when measuring blood pressure, the supine position should be taken to avoid errors. 


\subsection{Intervention Method}

Control group: After PCI, according to AMI and interventional treatment, the limbs of the operation side were completely braked for 12 hours, and the bed was absolutely bedridden for 3 days. Afterwards, activities were gradually increased, and psychological nursing and health education were given. The rehabilitation team advanced early rehabilitation care based on routine care.

On the first day after the operation, the bed movement: 14 to 6 hours after the operation, the patient was supine, the nurse assisted the patient to perform the body translation, and the bed was leveled and raised 15 to $30^{\circ}$ alternately, once every $1 \sim 2 \mathrm{~h}$, and assisted in the lower back. The kneading massage of the pressed part, the position change is subject to the patient's comfort. And guide other passive and active movements of unconstrained joints. After 26 hours, the nurse pressed the puncture point and the patient performed the main joints (such as the toes and ankles) on the bed. After $312 \mathrm{~b}$, the patient is assisted to make the side of the limb parallel movement, and to the side of the healthy side, etc., the position change must make the patient feel comfortable. A nurse who is not accustomed to lying urinating can use his hand to press the puncture point to adjust the lying position to facilitate urination. 412 to 24 hours after surgery can be raised high bed head $30^{\circ}$, the operation side of the lateral side of the alternate position, does not strictly limit the extension of the limb side of the limb, autonomous activities on the side of the limb, but the action should not be too fierce, the amplitude should not be too large. 5 Church patients to take a deep breath, 2 times a day. Guiding multiple drinking water is conducive to the excretion of contrast agents, and psychological rehabilitation and common sense missions are relieved.

On the second postoperative day, the patient sat on the bed and fed himself. When he started sitting, he could rely on it, such as putting a pillow or quilt on the back or raising the bed. Actively turning over, sitting on the bed or in a semi-recumbent position; starting respiratory muscle training, mainly abdominal breathing, uniformity between exhalation and inhalation, can be relatively slow, but not suffocating. Part of life is self-care (including self-feeding on the bed, grooming with the help of others); psychological rehabilitation and common sense missions, keeping the bowel movements smooth.

On the third day after the operation, the lower limbs were suspended by the bed, 3 to 4 times/day, 5 to 15 minutes each time. The limbs, eating, washing, brushing, and dressing were equivalent to regular activities. Sitting on the chair for 1 hour, getting out of bed Standing, bedside and hanging feet allow to get out of bed, allowing to read newspapers. Psychological rehabilitation and common sense missions introduce the pathogenesis and risk factors of coronary heart disease (hypertension, diabetes, hyperlipidemia, smoking, etc.). The role of the drugs used, methods of use and precautions [8].

Suspension of rehabilitation during the following conditions: 1 pre-cardiac discomfort, pain, shortness of breath or palpitations. 2 heart rate $>$ rest heart rate +20 , or $>110$ times / min. 3 systolic blood pressure increased by $\geq 30 \mathrm{mmHg}$ or decreased by $\geq 20 \mathrm{mmHg}$. 4 vertigo, dizziness and other symptoms of cerebral ischemia. 5 ECG ST segment ischemic downshift $\geq 0.2 \mathrm{mV}$, or when it is quieter, move down $\geq 0.1 \mathrm{mV}$, ST segment rise $\geq 0.2 \mathrm{mV}$. 6 severe arrhythmia. 7 Self-conscious fatigue (RPE $\geq 14$ ), 6 to 8 minutes after exercise, breathing, heart rate can not be restored to the state before exercise, or cause insomnia, prolonged fatigue, edema. During the activity, the heart rate, blood pressure, ECG changes, angina pectoris, heart failure, etc. are closely observed. If the above situation occurs, the activity is immediately stopped.

\subsection{Data Processing Method}

The measurement data were expressed as the mean standard deviation $\pm \mathrm{s}$, and the $\mathrm{t}$ test was used. The comparison of the data rates of each count was performed by $\mathrm{X} 2$ test. $\mathrm{P}<0.05$ is significant for the difference, and the statistical data is calculated by SPSS 13. O statistical software.

\section{Results}

\subsection{Comparison of General Information}

There were no significant differences in gender, age, cardiac function, and the number of coronary artery lesions between the two groups $(\mathrm{P}>0.05)$, as shown in Table 1 .

Table 1. Comparison of general data between the two groups of patients.

\begin{tabular}{llll}
\hline Project & & Control group (n/\%) & Rehabilitation group (n/\%) \\
\hline Number of cases & & 50 & 50 \\
Age & Male & $62.18 \pm 16.67$ & $60.83 \pm 15.92$ \\
Sex & Female & $27 / 54.00$ & $25 / 50.00$ \\
& I & $23 / 46.00$ & $25 / 50.00$ \\
Killip Rating & II & $39 / 78.00$ & $41 / 82.00$ \\
& 1 & $11 / 22.00$ & $9 / 18.00$ \\
Coronary artery disease count & 2 & $33 / 66.00$ & $34 / 38.00$ \\
& 3 & $12 / 24.00$ & $13 / 26.00$ \\
\hline
\end{tabular}

\subsection{Comparison of Preoperative Hemodynamic Parameters Between Rehabilitation Group and Control Group}

The hemodynamic parameters of the two groups were compared before operation, and there was no significant difference between the rehabilitation group and the control group before the PCI $(\mathrm{P}>0.05)$, suggesting that the two groups had no significant preoperative cardiac function. Differences 
are shown in Table 2.

Table 2. Comparison of preoperative PCI hemodynamic parameters between the rehabilitation group and the control group ( $x \pm s)$.

\begin{tabular}{llll}
\hline Project & Control group $(\mathbf{n}=\mathbf{5 0})$ & Rehabilitation $(\mathbf{n}=\mathbf{5 0})$ & P \\
\hline Heart rate $(\mathrm{HR})[\mathrm{min}]$ & $68.5 \pm 7.4$ & $69.4 \pm 7.8$ & 0.683 \\
Systolic blood pressure (SBP)[mmHg] & $127.6 \pm 11.8$ & $125.7 \pm 11.4$ & 0.749 \\
Diastolic blood pressure (DBP)[mmHg] & $85.1 \pm 10.3$ & $82.9 \pm 10.4$ & 0.607 \\
Mean arterial pressure $(\mathrm{MAP})[\mathrm{mmHg}]$ & $94.7 \pm 9.6$ & $96.2 \pm 9.4$ & 0.663 \\
Cardiac output $(\mathrm{CO})\left[\mathrm{L} \cdot \mathrm{min}^{-1}\right]$ & $5.1 \pm 1.1$ & $5.0 \pm 1.1$ & 0.836 \\
Cardiac index $(\mathrm{CI})\left[\mathrm{L} /\left(\mathrm{min}^{2} \cdot \mathrm{m}^{2}\right)\right]$ & $3.8 \pm 0.9$ & $3.4 \pm 0.8$ & 0.586 \\
Stroke output $(\mathrm{SV})[\mathrm{mL} / \mathrm{B}]$ & $67.3 \pm 8.7$ & $71.6 \pm 9.1$ & 0.375 \\
Stroke index $(\mathrm{Sl})\left[\mathrm{mL} /\left(\mathrm{B} \cdot \mathrm{m}^{2}\right)\right]$ & $40.1 \pm 7.9$ & $38.7 \pm 7.2$ & 0.439 \\
Left ventricular work $(\mathrm{LCW})[\mathrm{kg} \times \mathrm{m}]$ & $4.9 \pm 1.1$ & $4.6 \pm 1.2$ & 0.397 \\
Work Power Index $(\mathrm{LCWI})\left[\mathrm{kg} \times \mathrm{m} \times \mathrm{m}^{-2}\right]$ & $2.6 \pm 1.3$ & $3.1 \pm 1.4$ & 0.186 \\
Left ventricular ejection time $(\mathrm{LVET})[\mathrm{ms}]$ & $264.9 \pm 13.4$ & $257.7 \pm 12.8$ & 0.647 \\
Shrinkage time ratio $(\mathrm{STR})$ & $0.81 \pm 0.16$ & $0.75 \pm 0.12$ & 0.215 \\
Body vascular resistance $(\mathrm{SVR})\left[\mathrm{D} \cdot \mathrm{S} \times \mathrm{cm}^{-5}\right]$ & $1182.5 \pm 375.9$ & $1296.7 \pm 363.8$ & 0.487 \\
Resistance Index(SVRI)[D.S $\left.\times \mathrm{cm}^{-5} \times \mathrm{m}^{-2}\right]$ & $2386.7 \pm 478.4$ & $2409.4 \pm 486.7$ & 0.560 \\
\hline
\end{tabular}

\subsection{Comparison of Hemodynamic Parameters Between the Rehabilitation Group and the Control Group on the First and Second Days After PCI}

Patients in the rehabilitation group and the control group on the 1 st and 2nd day after PCI, HR (/min), SBP (mmHg), DBP $(\mathrm{mmHg})$, MAP $(\mathrm{mmHg}), \mathrm{STR}, \mathrm{SVR}(\mathrm{DS} \times \mathrm{cm}-5), \mathrm{SVRI}$ $(\mathrm{DS} \times \mathrm{cm}-5 \times \mathrm{m}-2)$ was significantly lower than that before surgery, but there was no significant difference between the two groups $(\mathrm{P}>0.05)$; $\mathrm{CO}(\mathrm{L} \cdot \mathrm{min}-1), \mathrm{CI}[\mathrm{L} /(\mathrm{min} \cdot \mathrm{m} 2)]$, $\mathrm{SV}(\mathrm{mL}$ / B), SI [mL / (B · m2)], LVET (ms), LCW $(\mathrm{kg} \times \mathrm{m})$, LCWI $(\mathrm{kg} \times \mathrm{m} \times \mathrm{m}-2)$ was significantly higher than before surgery, but two There was no significant difference between the groups $(\mathrm{P}>0.05)$, as shown in Table 3 and Table 4 .

Table 3. Comparison of hemodynamic parameters between the rehabilitation group and the control group on the first day after PCI.

\begin{tabular}{|c|c|c|c|}
\hline Project & Control group $(n=50)$ & Rehabilitation $(\mathrm{n}=\mathbf{5 0})$ & $\mathbf{P}$ \\
\hline Heart rate $(\mathrm{HR})[\mathrm{min}]$ & $67.4 \pm 7.8$ & $68.9 \pm 7.6$ & 0.615 \\
\hline Systolic blood pressure (SBP) $[\mathrm{mmHg}]$ & $127.3 \pm 12.6$ & $123.5 \pm 12.7$ & 0.722 \\
\hline Diastolic blood pressure (DBP) $[\mathrm{mmHg}]$ & $84.7 \pm 10.3$ & $83.2 \pm 10.6$ & 0.607 \\
\hline Mean arterial pressure (MAP) $[\mathrm{mmHg}]$ & $93.8 \pm 9.7$ & $95.7 \pm 9.3$ & 0.641 \\
\hline Cardiac output $(\mathrm{CO})\left[\mathrm{L} \cdot \mathrm{min}^{-1}\right]$ & $5.2 \pm 1.2$ & $5.4 \pm 1.3$ & 0.736 \\
\hline Cardiac index $(\mathrm{CI})\left[\mathrm{L} /\left(\mathrm{min} \cdot \mathrm{m}^{2}\right)\right]$ & $4.0 \pm 0.9$ & $3.5 \pm 0.8$ & 0.535 \\
\hline Stroke output (SV) $[\mathrm{mL} / \mathrm{B}]$ & $68.5 \pm 8.7$ & $72.4 \pm 9.1$ & 0.318 \\
\hline Left ventricular work $(\mathrm{LCW})[\mathrm{kg} \times \mathrm{m}]$ & $5.2 \pm 1.1$ & $4.7 \pm 1.2$ & 0.364 \\
\hline Work Power Index $(\mathrm{LCWI})\left[\mathrm{kg} \times \mathrm{m} \times \mathrm{m}^{-2}\right]$ & $2.7 \pm 1.3$ & $3.3 \pm 1.4$ & 0.128 \\
\hline Left ventricular ejection time (LVET)[ms] & $272.4 \pm 12.6$ & $261.5 \pm 12.9$ & 0.634 \\
\hline Shrinkage time ratio (STR) & $0.81 \pm 0.17$ & $0.75 \pm 0.14$ & 0.372 \\
\hline Body vascular resistance (SVR) $\left[\mathrm{D} . \mathrm{S} \times \mathrm{cm}^{-5}\right]$ & $1073.7 \pm 354.8$ & $1205.1 \pm 362.6$ & 0.442 \\
\hline Resistance Index(SVRI)[D.S $\left.\times \mathrm{cm}^{-5} \times \mathrm{m}^{-2}\right]$ & $2296.1 \pm 458.2$ & $2402.5 \pm 472.5$ & 0.475 \\
\hline
\end{tabular}

Table 4. Comparison of hemodynamic parameters between the rehabilitation group and the control group on the second day after PCI.

\begin{tabular}{|c|c|c|c|}
\hline Project & Control group $(n=50)$ & Rehabilitation $(n=50)$ & $\mathbf{P}$ \\
\hline Heart rate $(\mathrm{HR})[\mathrm{min}]$ & $66.7 \pm 7.9$ & $68.3 \pm 7.7$ & 0.636 \\
\hline Systolic blood pressure (SBP) $[\mathrm{mmHg}]$ & $125.6 \pm 12.4$ & $122.8 \pm 12.6$ & 0.728 \\
\hline Diastolic blood pressure (DBP) $[\mathrm{mmHg}]$ & $83.8 \pm 10.7$ & $82.1 \pm 10.9$ & 0.638 \\
\hline Mean arterial pressure (MAP) $[\mathrm{mmHg}]$ & $93.3 \pm 9.4$ & $95.1 \pm 9.5$ & 0.626 \\
\hline Cardiac output $(\mathrm{CO})\left[\mathrm{L} \cdot \mathrm{min}^{-1}\right]$ & $5.5 \pm 1.1$ & $6.1 \pm 1.2$ & 0.594 \\
\hline Cardiac index $(\mathrm{CI})\left[\mathrm{L} /\left(\min \cdot \mathrm{m}^{2}\right)\right]$ & $4.5 \pm 1.1$ & $3.8 \pm 0.9$ & 0.497 \\
\hline Stroke output (SV)[mL/B] & $69.5 \pm 9.4$ & $73.2 \pm 9.8$ & 0.365 \\
\hline Stroke index $(\mathrm{SI})\left[\mathrm{mL} /\left(\mathrm{B} \cdot \mathrm{m}^{2}\right)\right]$ & $42.1 \pm 8.5$ & $39.3 \pm 8.1$ & 0.372 \\
\hline Left ventricular work $(\mathrm{LCW})[\mathrm{kg} \times \mathrm{m}]$ & $5.6 \pm 1.3$ & $4.9 \pm 1.3$ & 0.351 \\
\hline Work Power Index $($ LCWI $)\left[\mathrm{kg} \times \mathrm{m} \times \mathrm{m}^{-2}\right]$ & $3.0 \pm 1.3$ & $3.8 \pm 1.4$ & 0.116 \\
\hline Left ventricular ejection time (LVET)[ms] & $278.6 \pm 11.7$ & $266.1 \pm 11.5$ & 0.582 \\
\hline Shrinkage time ratio (STR) & $0.76 \pm 0.16$ & $0.72 \pm 0.12$ & 0.386 \\
\hline Body vascular resistance (SVR) [D.S $\left.\times \mathrm{cm}^{-5}\right]$ & $1076.8 \pm 368.9$ & $1189.8 \pm 359.2$ & 0.457 \\
\hline Resistance Index(SVRI)[D.S $\left.\times \mathrm{cm}^{-5} \times \mathrm{m}^{-2}\right]$ & $2275.9 \pm 464.3$ & $2386.1 \pm 475.2$ & 0.489 \\
\hline
\end{tabular}




\subsection{Comparison of Hemodynamic Parameters Between the Rehabilitation Group and the Control Group on the 3rd Day After PCI}

Rehabilitation group and control group on the 3rd day after PCI, HR (min-1), SBP (mmHg), DBP (mmHg), STR, SVR $(\mathrm{DS} \times \mathrm{cm}-5)$, SVRI (DS $\times \mathrm{cm}-5 \times \mathrm{M}-2)$ was significantly lower than preoperative, but there was no significant difference between the two groups $(\mathrm{P}>0.05)$. $\mathrm{CI}[\mathrm{L} /(\mathrm{min} \cdot \mathrm{m} 2)]$, $\mathrm{SV}(\mathrm{mL} / \mathrm{B}), \mathrm{SI}[\mathrm{mL} /(\mathrm{B} \cdot \mathrm{m} 2)], \operatorname{LVET}(\mathrm{ms}), \operatorname{LCW}(\mathrm{kg} \times \mathrm{m}), \mathrm{LCWI}$ $(\mathrm{kg} \times \mathrm{m} \times \mathrm{m}-2))$ was significantly higher than before, but there was no significant difference between the two groups $(\mathrm{P}>0.05)$. However, after rehabilitation, the cardiac output of $\mathrm{CO}$ increased significantly compared with preoperative, and the difference between the two groups was statistically significant $(\mathrm{P}<0.05)$. The mean arterial pressure MAP was significantly lower than that before surgery, and there were statistical differences between the two groups. The meaning of learning $(\mathrm{P}<0.05)$, see Table 5 .

Table 5. Comparison of hemodynamic parameters between the rehabilitation group and the control group on the 3 th day after PCI.

\begin{tabular}{|c|c|c|c|}
\hline Project & Control group $(n=50)$ & Rehabilitation $(n=50)$ & $\mathbf{P}$ \\
\hline Heart rate $(\mathrm{HR})[\mathrm{min}]$ & $66.5 \pm 7.8$ & $67.3 \pm 7.6$ & 0.672 \\
\hline Systolic blood pressure (SBP) $[\mathrm{mmHg}]$ & $124.5 \pm 12.4$ & $122.6 \pm 12.8$ & 0.694 \\
\hline Diastolic blood pressure (DBP) $[\mathrm{mmHg}]$ & $83.1 \pm 9.5$ & $80.2 \pm 9.8$ & 0.526 \\
\hline Cardiac output $(\mathrm{CO})\left[\mathrm{L} \cdot \mathrm{min}^{-1}\right]$ & $5.6 \pm 1.1$ & $7.1 \pm 1.3$ & 0.026 \\
\hline Cardiac index $(\mathrm{CI})\left[\mathrm{L} /\left(\min \cdot \mathrm{m}^{2}\right)\right]$ & $4.3 \pm 1.1$ & $3.7 \pm 1.0$ & 0.488 \\
\hline Stroke output (SV)[mL/B] & $69.8 \pm 9.4$ & $73.3 \pm 9.8$ & 0.402 \\
\hline Left ventricular work $(\mathrm{LCW})[\mathrm{kg} \times \mathrm{m}]$ & $5.4 \pm 1.2$ & $4.8 \pm 1.3$ & 0.373 \\
\hline Work Power Index $(\mathrm{LCWI})\left[\mathrm{kg} \times \mathrm{m} \times \mathrm{m}^{-2}\right]$ & $2.9 \pm 1.4$ & $3.6 \pm 1.5$ & 0.157 \\
\hline Left ventricular ejection time (LVET)[ms] & $269.2 \pm 13.7$ & $261.4 \pm 13.6$ & 0.613 \\
\hline Shrinkage time ratio (STR) & $0.76 \pm 0.14$ & $0.73 \pm 0.13$ & 0.207 \\
\hline Body vascular resistance (SVR) [D.S $\left.\times \mathrm{cm}^{-5}\right]$ & $1043.3 \pm 368.1$ & $1187.5 \pm 359.2$ & 0.452 \\
\hline Resistance Index(SVRI)[D.S $\left.\times \mathrm{cm}^{-5} \times \mathrm{m}^{-2}\right]$ & $2276.3 \pm 463.7$ & $2356.4 \pm 474.9$ & 0.518 \\
\hline
\end{tabular}

\subsection{Rehabilitation and Complications of PCI Patients in the Rehabilitation Group and the Control Group}

There was no significant difference in the incidence of vascular complications between the rehabilitation group and the control group $(\mathrm{P}>0.05)$. The postoperative bed coordination and urination in the rehabilitation group were significantly better than those in the control group $(\mathrm{P}<0.05)$. The degree of discomfort was significantly higher than that of the control group $(\mathrm{P}<0.05)$, and the degree of relief of back pain was more significant than that of the control group $(\mathrm{P}<$ 0.05). See Table 6 for details.

Table 6. Comparison of comfort and complications after PCI in the group and control group (n/\%).

\begin{tabular}{lllllll}
\hline Group & Number of cases & Irritability & Bloating & Dysuria & Low back pain & Puncture point bleeding, hematoma \\
\hline $\begin{array}{l}\text { Rehabilitation } \\
(\mathrm{n}=50)\end{array}$ & 50 & $8 / 16.00$ & $5 / 10.00$ & $7 / 14.00$ & $11 / 22.00$ & $4 / 8.00$ \\
$\begin{array}{l}\text { Control group } \\
(\mathrm{n}=50)\end{array}$ & 50 & $31 / 62.00$ & $16 / 32.00$ & $28 / 56.00$ & $39 / 78.00$ & $6 / 12.00$ \\
$\mathrm{P}$ & & 0.007 & 0.011 & 0.003 & 0.002 & 0.377 \\
\hline
\end{tabular}

\section{Discussion}

After acute myocardial infarction, local myocardial ischemia and necrosis are prone to complications such as heart failure and arrhythmia. According to the traditional treatment point of view, patients with AMI need absolute bed rest for one week after surgery to reduce myocardial oxygen consumption and reduce cardiac load [9]. However, with the in-depth development of interventional techniques, emergency PCI can re-infuse the diseased vessels and reduce the chance of restenosis, so that the myocardium in the stunned regained blood supply and resurrection [10]. Successful surgery provides favorable conditions for early rehabilitation exercise in patients with acute myocardial infarction, so the rehabilitation of coronary heart disease also progresses from the rehabilitation of traditional myocardial infarction to the rehabilitation of coronary heart disease after interventional therapy [11].

Domestic and foreign studies have shown that patients after percutaneous coronary intervention (PCI) are suitable for cardiac rehabilitation [12]. From the perspective of nursing, early rehabilitation care after acute myocardial infarction can achieve the following goals: reduce the adverse effects of absolute bed rest on muscle and cardiovascular regulation, prevent venous thrombosis and embolism, reduce depression and anxiety, and promote physical recovery. Reduce the incidence of restenosis and cardiovascular events [13]. The postoperative recovery of PCI patients is related to the experience and technology of the surgeon, and is closely related to the quality of clinical care [14]. Although the patient's stenotic coronary artery was dilated after PCI, myocardial perfusion was improved. However, most patients still have limited mobility and psychological disorders during postoperative rehabilitation. Strengthening the postoperative rehabilitation of PCI 
patients is of great significance in promoting the physiological and psychological recovery of patients after surgery [15]. Due to the high dose of heparin in PCI and the damage caused by arterial puncture, the application of antiplatelet and anticoagulant drugs after surgery, and the improper hemostasis after the extraction of the arterial sheath, the patient has local hemorrhage and hematoma after puncture. Possible [16]. Therefore, the patient is required to have a long limb braking time during bed rest, and has been in a forced position, with high mental stress and great ideological pressure, which may easily lead to physical discomfort such as urinary retention, waist pain and general discomfort; Long-term bed rest can also cause "disorder", including the reduction of physical activity, labor caused by inappropriate heart rate response, reduced ability to adapt to changing position, easy to cause orthostatic hypotension, decreased circulating blood volume and decreased muscle contractility Long-term bed rest is also prone to thromboembolism and mood abnormalities (such as anxiety and depression) [17-18]. Rehabilitation exercise regulates the sympathetic nervous system and renin angiotensin-aldosterone system through regular aerobic exercise, reduces systolic blood pressure and heart rate at rest, reduces myocardial oxygen consumption, reduces peripheral blood vessel tension, and increases cardiac output. Volume, improve coronary system blood supply [19-20]. Studies have shown that the effective mechanism of rehabilitation exercise may be that exercise significantly reduces vascular endothelin levels, increases blood nitric oxide, calcitonin gene-related peptide levels, increases plasmin activity, reduces platelet activity, inhibits smooth muscle cell proliferation, and thus expands Coronary arteries increase exercise reserve, reduce coronary thrombosis, and reduce or reverse arteriosclerotic lesions [21]. At the same time, health education has better increased the control of risk factors for arteriosclerosis such as weight, blood sugar, blood lipids, high blood pressure and smoking; mental health guidance has improved the nervous system function regulation, increased confidence and confidence in combating the disease and Treatment coordination [22-23].

In this study, the hemodynamic parameters of the two groups in the rehabilitation group and the control group were found to be no significant difference between the two groups, suggesting that the rehabilitation nursing program implemented in this study did not affect the patient's postoperative heart. The function has an impact. The heart function of the rehabilitation group did not deteriorate due to exercise, indicating that early exercise training after PCI is safe. On the third day after the operation, the cardiac output of the patient increased significantly, and the average arterial pressure foot decreased significantly, indicating that the rehabilitation exercise is beneficial to the improvement of cardiac function. Through deep breathing, abdominal and chest breathing training in this rehabilitation training, it helps to strengthen the muscle strength of the respiratory muscles, expand the range of thoracic motion, especially increase the distance of the diaphragm muscles, effectively expand the airway, reduce respiratory resistance, and improve Respiratory quality, and can further improve the heart function of patients, the possible mechanisms include: due to improved lung function, increased oxygen saturation, more beneficial to improve skeletal muscle function, increase mitochondria number, volume and activity, and make skeletal muscle oxygen utilization Increased arteriovenous oxygen difference, increased functional reserve, and increased aerobic capacity of the body, which promotes myocardial contractile function and cardiac output [24-25]. The mechanism of mean arterial pressure reduction may also be associated with increased vagal tone and decreased plasma norepinephrine levels [26].

In addition, exercise can dilate peripheral blood vessels, increase tissue perfusion, lower blood pressure, further improve coronary blood flow, increase myocardial blood supply, thereby improving the symptoms of myocardial ischemia, and is conducive to cardiac function recovery [27]. In addition, the patient's muscle contraction during the rehabilitation exercise promotes venous return, which increases the amount of blood return [28]. At the same time, regular aerobic exercise can lower cholesterol levels, stabilize plaque, improve vascular endothelial function and NO/ET-1 ratio, and increase PG12 synthesis and release of vascular endothelium. PG12 has anti-platelet aggregation and vasodilation effects. Coordination of coronary heart disease after drug intervention can alleviate or prevent the development of coronary atherosclerosis, prevent the formation of subacute thrombosis after stent implantation, reduce complications, reduce readmission rate and sudden death rate [29-30].

\section{Conclusion}

In summary, the chest impedance method for non-invasive monitoring of acute myocardial infarction hemodynamics can be used as an important objective indicator for the success of PCI, and can also guide the implementation of early PCI rehabilitation care in patients with acute myocardial infarction to ensure safety. And there is no pain to the patient, no need to move the patient and the method is simple, reliable, reproducible and easy to promote.

\section{References}

[1] Kala P. Kanovsky J. et al. Age-related treatment strategy and long-term outcome in acute myocardial infarction patients in the PCI era [J]. BMC Cardiovasc Disord, 2018, $12(2): 31-3$

[2] Stone GW. Witzenbichler B. et al. Bivalirudin during primary PCI in acute myocardial infarction [J]. N Engl J Med, 2018, 358 (21): 2218-30.

[3] Antoniucci D. Valenti R. et al. Thrombectomy during PCI for acute myocardial infarction: are the randomized controlled trial data relevant to the patients who really need this technique? [J]. Catheter Cardiovasc Interv, 2018, 71 (7): 863-9. 
[4] Moscucci M. Public reporting of PCI outcomes and quality of care: one step forward and new questions raised [J]. JAMA, 2017, 308 (14): 1478-9.

[5] Maier B. Behrens S. et al. Time of admission, quality of PCI care, and outcome of patients with ST-elevation myocardial infarction [J]. Clin Res Cardiol, 2018, 99 (9): 565-72.

[6] Hassan AK. Liem SS. et al. In-ambulance abciximab administration in STEMI patients prior to primary PCI is associated with smaller infarct size, improved LV function and lower incidence of heart failure: results from the Leiden MISSION! acute myocardial infarction treatment optimization program [J]. Catheter Cardiovasc Interv, 2017, 74 (2): 335-43.

[7] Shaikh AH. Siddiqui MS. et al. Outcomes of primary percutaneous coronary intervention (PCI) in a tertiary care cardiac centre [J]. J Pak Med Assoc, 2018, 59 (7): 426-9.

[8] Mills C. Wright C. et al. Care of the post percutaneous coronary intervention patien t [J]. Aust Nurs J, 2019, 19 (7): 26-7.

[9] Post S. Post MC. et al. Early statin treatment prior to primary PCI for acute myocardial infarction: REPERATOR, a randomized placebo-controlled pilot trial [J]. Catheter Cardiovasc Interv, 2019, 80 (5): 756-65.

[10] Hofma SH. Brouwer J. et al. Second-generation everolimus-eluting stents versus first-generation sirolimus-eluting stents in acute myocardial infarction. 1-year results of the randomized XAMI (XienceV Stent vs. Cypher Stent in Primary PCI for Acute Myocardial Infarction) trial [J]. J Am Coll Cardiol, 2018, 60 (5): 381-7.

[11] Monhart Z. Grunfeldova H. et al. Pilot register of acute myocardial infarction--a 5-year evaluation of quality of care in non-PCI hospitals [J]. Vnitr Lek, 2018, 56 (1): 21-9.

[12] Sjauw KD. Stegenga NK. et al. The influence of gender on short- and long-term outcome after primary PCI and delivered medical care for ST-segment elevation myocardial infarction [J]. EuroIntervention, 2019, 5 (7): 780-7.

[13] Cho MY. Min ES. et al. Effects of aromatherapy on the anxiety, vital signs, and sleep quality of percutaneous coronary intervention patients in intensive care units $[\mathrm{J}]$. Evid Based Complement Alternat Med, 2018, 16(2): 381-3.

[14] Miric D. Novak K. et al. In-hospital mortality of patients with acute myocardial infarction before and after introduction of PCI in Split University Hospital Center, Croatia [J]. Coll Antropol, 2018, 37 (1): 207-12.

[15] Escarcega R0. Bashir R. et al. Transradial coronary angiography and percutaneous intervention in the era of health care reform, cost containment, and patient-centered care [J]. J Invasive Cardiol, 2017, 23 (9): 383-5.

[16] Solheim S. Seljeflot I. et al. Prothrombotic markers in patients with acute myocardial infarction and left ventricular thrombus formation treated with pci and dual antiplatelet therapy [J]. Thromb J, 2018, 11 (1):1-3.

[17] Bagai A. Cantor WJ. et al. Clinical outcomes and cost implications of routine early PCI after fibrinolysis: one-year follow-up of the Trial of Routine Angioplasty and Stenting after Fibrinolysis to Enhance Reperfusion in Acute Myocardial
Infarction (TRANSFER-AMI) study [J]. Am Heart J, 2018, 165 (4): 630-637.

[18] Bauer T. Zeymer U. et al. Use and outcomes of multivessel percutaneous coronary intervention in patients with acute myocardial infarction complicated by cardiogenic shock (from the EHS-PCI Registry) [J]. Am J Cardiol, 2018, 109 (7): 941-6.

[19] Kawasuji M. Debate over patient-centered care: percutaneous coronary intervention or coronary artery bypass grafting?[J]. Surg Today, 2018, 41 (4): 459-62

[20] Patterson T. Foale RA. If the radial artery is the new standard of care in primary percutaneous coronary intervention, why is most intervention done by the femoral approach [J]. Heart, 2017, 97 (7): 521-2.

[21] Zimarino M. Ruggieri B. et al. Patient management and care after primary percutaneous coronary intervention: reinforcing a continuum of care after primary percutaneous coronary intervention [J]. Am Heart J, 2017, 160 (6): 42-7.

[22] Huang YH. Chen CH. Nursing experience providing care for back pain following percutaneous coronary intervention[J]. Hu Li Za Zhi, 2017, 57 (2): 75-80.

[23] Amoroso G. Kiemeneij F. Transradial access for primary percutaneous coronary intervention: the next standard of care? [J]. Heart, 2018, 96 (17): 1341-4.

[24] Zeymer U. Bauer T. et al. Use and impact of intra-aortic balloon pump on mortality in patients with acute myocardial infarction complicated by cardiogenic shock: results of the Euro Heart Survey on PCI [J]. EuroIntervention, 2018, 7 (4): 437-41.

[25] Jeger RV. Pfisterer ME. et al. Primary PCI in STEMI--dilemmas and controversies: multivessel disease in STEMI patients. Complete versus Culprit Vessel revascularization in acute ST--elevation myocardial infarction [J]. Minerva Cardioangiol, 2018, 59 (3): 225-33.

[26] Zanchi J. Miric D. et al. Gender differences in in-hospital mortality and angiographic findings of patients with acute ST-segment elevation myocardial infarction (STEMI) undergoing percutaneous coronary intervention $(\mathrm{PCI})[\mathrm{J}]$. Coll Antropol, 2019, 33 (4): 1359-62.

[27] Mullasari A. Strategy of in ambulance thrombolysis followed by routine PCI in acute myocardial infarction [J]. Indian Heart J, 2019, 61(5): 448-53.

[28] Rolley JX. Salamonson Y. et al. Nursing care practices following a percutaneous coronary intervention: results of a survey of Australian and New Zealand cardiovascular nurses [J]. J Cardiovasc Nurs, 2018, 25 (1): 75-84.

[29] Mangiacapra F. Barbato E. et al. Point-of-care assessment of platelet reactivity after clopidogrel to predict myonecrosis in patients undergoing percutaneous coronary intervention $[\mathrm{J}]$. JACC Cardiovasc Interv, 2019, 3 (3): 318-23.

[30] Rolley JX. Davidson PM. et al. Review of nursing care for patients undergoing percutaneous coronary intervention: a patient journey approach [J]. J Clin Nurs, 2019, 18 (17): 2394-405. 